\title{
Carbide Phases Synthesised from C/Mo Powder Compacts at Specified Sub-Stoichiometric Ratios by Solar Radiation Heating to Temperatures between $1600^{\circ} \mathrm{C}$ and $2500^{\circ} \mathrm{C}$
}

\author{
Bernard Granier ${ }^{1}$, Nobumitsu Shohoji ${ }^{2, *}$, Fernando Almeida Costa Oliveira ${ }^{2,3}$, \\ Teresa Magalhães ${ }^{2}$, Jorge Cruz Fernandes ${ }^{3}$ and Luis Guerra Rosa ${ }^{3}$ \\ ${ }^{1}$ Laboratoire Procédés, Materiaux, Energie Solaire, PROMES-CNRS, 7, rue du Four Solaire, Odeillo 66120, France \\ ${ }^{2}$ LNEG-Laboratório Nacional de Energia e Geologia, LEN-Laboratório de Energia, \\ Estrada do Paço do Lumiar No. 22, 1649-038 Lisboa, Portugal \\ ${ }^{3}$ Departamento de Engenharia de Materiais, Instituto Superior Técnico, Av. Rovisco Pais, 1049-001 Lisboa, Portugal
}

\begin{abstract}
There are a number of distinguishable carbide phases in the binary Mo-C system depending on $\mathrm{C} /$ Mo ratio as well as on temperature. In a preceding work published in this journal, carbide formation performance for graphite/molybdenum powder mixtures at specified levels of substoichiometric $\mathrm{C} /$ Mo atom ratio $(\mathrm{C} / \mathrm{Mo}=1 / 1,3 / 4,2 / 3$ and $1 / 2)$ by exposure to concentrated solar radiation in a solar furnace at PROMESCNRS in Odeillo (France) was reported at a target temperature $1900^{\circ} \mathrm{C}$. In the present work, the similar carbide synthesis experiments were carried out at $1600^{\circ} \mathrm{C}$ as well as at temperature exceeding $2500^{\circ} \mathrm{C}$. The target temperature setting was adjusted by controlling the downward deviation of the test piece top surface position from the exact focal spot of the parabolic mirror concentrator located above. In this solar furnace at PROMES-CNRS, temperature of the test piece was raised from ambient temperature to the target temperature within fractions of a second. Reaction products detected were hexagonal $\eta-\mathrm{MoC}_{1-x}$ and $\beta-\mathrm{Mo}_{2} \mathrm{C}$ (high temperature sub-carbide phase) depending on the $\mathrm{C} / \mathrm{Mo}$ ratio in the starting material as well as on the processing temperature. No evidence of formation of cubic $\alpha-\mathrm{MoC}_{1-x}$ was detected by X-ray diffraction analysis for any test piece examined. [doi:10.2320/matertrans.M2009167]
\end{abstract}

(Received May 7, 2009; Accepted September 8, 2009; Published October 28, 2009)

Keywords: molybdenum carbides, non-stoichiometry, solar furnace, ultra-fast heating

\section{Introduction}

In our preceding work, ${ }^{1)}$ compacted powder mixtures of graphite and molybdenum at specified hypo-stoichiometric composition ratios, $\mathrm{C} / \mathrm{Mo}=1 / 2,2 / 3,3 / 4$ and $1 / 1$, were heated to $1900^{\circ} \mathrm{C}$ in a solar furnace at PROMES-CNRS in Odeillo (France) to be converted to carbide $\mathrm{MoC}_{1-x}$. Under the employed experimental condition with the target temperature $1900^{\circ} \mathrm{C}$, yield of $\eta-\mathrm{MoC}_{1-x}$ was comparatively high for the specimen with the $\mathrm{C} / \mathrm{Mo}$ atom ratio set at $2 / 3$ (close to the composition of the hexagonal $\eta-\mathrm{MoC}_{1-x}$ ) as well as at $3 / 4$ (close to the composition of the cubic $\alpha$ $\mathrm{MoC}_{1-x}$ ) while $\beta-\mathrm{Mo}_{2} \mathrm{C}$ phase was present insistently for any test piece examined. Yield of $\beta-\mathrm{Mo}_{2} \mathrm{C}$ (high temperature sub-carbide phase) under the solar-synthesis condition with the target temperature $1900^{\circ} \mathrm{C}$ was specially high for the test piece started with $\mathrm{C} / \mathrm{Mo}=1 / 1$ as well as for the test piece started with $\mathrm{C} / \mathrm{Mo}=1 / 2$ while it was comparatively low with the test pieces started from $\mathrm{C} / \mathrm{Mo}=2 / 3$ and $3 / 4{ }^{1)}$

In our earlier work on solar Mo carbide synthesis under condition of presence of excess free carbon at the end of the reaction, ${ }^{2)}$ identification for the XRD peaks of $\mathrm{Mo}_{2} \mathrm{C}$ phase was done erroneously to be the $\alpha-\mathrm{Mo}_{2} \mathrm{C}$ phase (low temperature $\mathrm{Mo}_{2} \mathrm{C}$ phase known to be stable at temperatures below $1430^{\circ} \mathrm{C}$ ) in place of the $\beta$-phase. The origins of this shameful mis-interpretation in the identification for the $\mathrm{Mo}_{2} \mathrm{C}$ phase in our earlier work ${ }^{2)}$ were as follows (cf. Table 1 in the preceding work ${ }^{1)}$ composed on the basis of the available information $^{3-5)}$ ):

*Corresponding author, E-mail: nobumitsu.shohoji@ineti.pt
(1) The XRD peak for the $\eta-\mathrm{MoC}_{1-x}(101)$ at $2 \theta=34.93^{\circ}$ was identified erroneously as the overlapped peak with $\alpha-\mathrm{Mo}_{2} \mathrm{C}(002)$ peak $\left(2 \theta=34.43^{\circ}\right)$,

(2) Correspondingly, the $\beta-\mathrm{Mo}_{2} \mathrm{C}(200)$ peak $\left(2 \theta=37.90^{\circ}\right)$ was erroneously considered to be $\alpha-\mathrm{Mo}_{2} \mathrm{C}$ (002) peak $\left(2 \theta=37.96^{\circ}\right)$.

Anyway, the results obtained in the earlier work $^{2)}$ appeared to imply the possibility to synthesise singlephase $\eta-\mathrm{MoC}_{1-x}$ without co-existence of $\beta-\mathrm{Mo}_{2} \mathrm{C}$ phase by adequate selection of reaction conditions in the solar radiation heating experiment. Non-stoichiometric composition range for the hexagonal $\eta-\mathrm{MoC}_{1-x}$ and that for the cubic $\alpha-\mathrm{MoC}_{1-x}$ are known to be around $\mathrm{C} / \mathrm{Mo}=0.70 .^{3-5}$ ) Thus, in the preceding work, ${ }^{1)}$ specimens with $\mathrm{C} / \mathrm{Mo}$ atom ratios at $1 / 1,3 / 4(=0.75), 2 / 3(=0.67)$ and $1 / 2$ were heated to $1900^{\circ} \mathrm{C}$ under concentrated solar beam radiation in the solar furnace at PROMES-CNRS aiming at identifying conditions leading to preferential formation of $\eta-\mathrm{MoC}_{1-x}$ phase. As reported in the preceding publication, ${ }^{1)}$ under any chosen compositional condition at processing temperature $1900^{\circ} \mathrm{C}$ for duration $30 \mathrm{~min}$, single-phase $\eta$ - $\mathrm{MoC}_{1-x}$ was not synthesized and $\beta-\mathrm{Mo}_{2} \mathrm{C}$ phase was always present, in some cases existing as single-phase without trace of $\eta-\mathrm{MoC}_{1-x}$ phase.

To look into the formation condition of $\eta-\mathrm{MoC}_{1-x}$ in further detail, we carried out the solar irradiation heating experiments for the powder compacts with $\mathrm{C} / \mathrm{M}$ atom ratios, $1 / 1,3 / 4,2 / 3$ and $1 / 2$, at $1600^{\circ} \mathrm{C}$ and also at " $2500^{\circ} \mathrm{C}$ ", in the present work. In fact, the so-called " $2500^{\circ} \mathrm{C}$ " test was undertaken by placing the test piece top surface at the exact focal spot of the parabolic mirror concentrator without encasing the test piece in graphite crucible unlike in the 
standard solar irradiation experiment. The background idea of this experimental setup was to apply all the heat of the concentrated solar beam exclusively to the test piece by minimising the dissipation of the heat to the surrounding sample holder. Naturally, near-black body radiation for the pyrometric temperature measurement condition was not fulfilled for the " $2500^{\circ} \mathrm{C}$ " test. Thus, the designated temperature $2500^{\circ} \mathrm{C}$ for the " $2500^{\circ} \mathrm{C}$ " test represents merely the situation that the nominal measured radiation temperature was no less than $2500^{\circ} \mathrm{C}$ and thence the real test piece temperature must have been by $100-200^{\circ} \mathrm{C}$ higher than the measured temperature by optical pyrometer, quite probably exceeding the melting temperature $2600^{\circ} \mathrm{C}$ of $\alpha-\mathrm{MoC}_{1-x}$ phase ${ }^{3-5)}$ noting the evidences indicating partial melting of the top surface of most of the test pieces.

The present experimental results showed that single-phase $\eta$ - $\mathrm{MoC}_{1-x}$ was prepared only from the $\mathrm{C} / \mathrm{Mo}=3 / 4$ specimen processed at " $2500^{\circ} \mathrm{C}$ " and all the other specimens contained $\beta-\mathrm{Mo}_{2} \mathrm{C}$. No evidence of formation of $\alpha-\mathrm{MoC}_{1-x}$ was detected by XRD in any specimen examined.

\section{Experimental}

The experimental setup used to perform the carbide synthesis experiments in the solar furnace at PROMESCNRS was described in detail elsewhere. ${ }^{1,2,6-8)}$ The compacted pellets of $\mathrm{C} / \mathrm{Mo}$ atom ratios set to be $1 / 2,3 / 4,2 / 3$ and $1 / 1$ with diameter $8 \mathrm{~mm}$ and height $5 \mathrm{~mm}$ were prepared by uni-axially pressing the powder mixtures at $450 \mathrm{MPa}$. Mo powder $(99.9 \%$ pure, mean particle size $2 \mu \mathrm{m})$ was supplied from Goodfellow, Ltd. (Cambridge, England) and graphite powder $(<50 \mu \mathrm{m})$ from E.Merck AG (Darmstadt, Germany). The compacted pellet specimen was placed in a specially designed crucible for the exposure to the concentrated solar beam (see Figs. 1 and 2 in Ref. 6) for the crucible). The reaction chamber (Pyrex glass; $5 l$ capacity) was flushed twice with inert $\mathrm{Ar}$ gas with grade $\mathrm{U}$ (nominal purity 99.999\% with $\mathrm{O}_{2}$ no higher than $5 \mathrm{ppm}$ and $\mathrm{H}_{2} \mathrm{O}$ also no higher than $5 \mathrm{ppm}$ ) before being filled with $460 \mathrm{mbar}$ $\left(4.6 \times 10^{4} \mathrm{~Pa}\right) \mathrm{Ar}$ gas at ambient temperature. It should be noted that the PROMES-CNRS facilities lies about $1500 \mathrm{~m}$ from the sea level and the atmospheric pressure there is normally $\mathrm{ca}$. $850 \mathrm{mbar}\left(8.5 \times 10^{4} \mathrm{~Pa}\right)$.

Like in the earlier experimental works performed at PROMES-CNRS, ${ }^{1,2,6-8)}$ the sample holder was brought into the hot spot of the solar furnace by sliding manually the reaction chamber over a pair of guiding rails. Within fractions of a second, the specimen temperature rose from ambient temperature to the target processing temperature. This ultra-fast heating rate at the onset of the concentrated solar beam radiation experiment is the unique characteristic of the solar furnace at PROMES-CNRS at Odeillo. In the earlier solar-carbide synthesis experiments done at PSA (Tabernas), it took about a few minutes to heat the specimen from ambient temperature to the target temperature depending on the rate of opening of the louvered shutter.9,10)

In cases of the experiments performed at the target temperatures, $1600^{\circ} \mathrm{C}$ and $1900^{\circ} \mathrm{C}$, the radiation temperature of the specimen material was measured through the triple vertical slits of width $1 \mathrm{~mm}$ cut in the graphite crucible using an optical pyrometer (Model 95 of Pyrometric Instrument Company, Inc., Bergenfield, N.J., USA) through a view window from the side of the Pyrex glass reaction chamber.

On the other hand, the experiments at the nominal target temperature " $2500^{\circ} \mathrm{C}$ " were undertaken by configuring the test piece top surface to be set at the exact focal spot of the parabolic mirror concentrator as pointed out earlier in the text. After the $2500^{\circ} \mathrm{C}$ test, the test piece top part showed deformation as the consequence of "macroscopic" melting whereas only evidence of "microscopic" or partial melting was detected for the test pieces processed at target temperature lower than $1900^{\circ} \mathrm{C}^{1,2)}$

After $30 \mathrm{~min}$ holding at the target temperature, the sample holder was taken away from the hot spot of the solar furnace and the specimen material was cooled down under flowing $\mathrm{Ar}$ gas. After about $30 \mathrm{~min}$, the Pyrex glass reaction chamber was opened to take out the specimen cooled down near ambient temperature. Then, the specimens were characterized by means of XRD and scanning electron microscopy (SEM).

Phase identification was made by XRD analysis using a Geigerflex D/MAX IIIC diffractometer (Rigaku International Corp., Japan) with $\mathrm{Cu} K \alpha$ radiation. For this purpose, as-synthesized specimens were stuck to a glass sheet surface and scanned over a range of $2 \theta$ from $25^{\circ}$ to $45^{\circ}$ at a scanning speed of $2^{\circ} 2 \theta \cdot \mathrm{min}^{-1}$. To ensure flatness of the test piece surface exposed to XRD characterization, top surface of the test piece processed at " $2500^{\circ} \mathrm{C}$ " showing deformation as the consequence of macroscopic melting had to be polished lightly.

The morphology of the specimen surface was inspected using a Field Emission Philips XL 30 FEG SEM operated with acceleration voltage 10 to $15 \mathrm{kV}$.

\section{Results and Discussion}

The XRD profiles obtained for the test pieces processed to the target temperature $1600^{\circ} \mathrm{C}$ are reproduced in Fig. 1 and those for the test pieces processed to the target temperature " $2500^{\circ} \mathrm{C}$ " in Fig. 2. Table 1 summarises the phases detected in the top and the bottom surfaces in the specimens at respective target temperatures. In Table 1, the data acquired at $1900^{\circ} \mathrm{C}$ are integrated taken from the preceding report. ${ }^{1)}$ The data for the " $2500^{\circ} \mathrm{C}$ " test pieces are incomplete (lacking the data for $\mathrm{C} / \mathrm{Mo}=2 / 3$ test piece) and thus might be considered merely as the reference data for comparison purpose.

Following features are noticed in Table 1.

(i) All the test piece top and bottom surfaces contained $\beta$ $\mathrm{Mo}_{2} \mathrm{C}$ phase besides $\eta$ - $\mathrm{MoC}_{1-x}$ phase in the reaction product except for the $\mathrm{C} / \mathrm{Mo}=3 / 4$ test piece top surface processed at " $2500^{\circ} \mathrm{C}$ " which was identified to be composed solely of the $\eta-\mathrm{MoC}_{1-x}$ phase.

(ii) The top and the bottom surface of the $\mathrm{C} / \mathrm{Mo}=1 / 2$ test piece processed at $1600^{\circ} \mathrm{C}$ were with $\beta-\mathrm{Mo}_{2} \mathrm{C}$ single phase.

(iii) Free metallic Mo was detected in the two specimens; the bottom surface of the $\mathrm{C} / \mathrm{Mo}=2 / 3$ test piece processed at $1600^{\circ} \mathrm{C}$ and the top surface of the $\mathrm{C} /$ $\mathrm{Mo}=1 / 2$ test piece processed at " $2500^{\circ} \mathrm{C}$ ". 


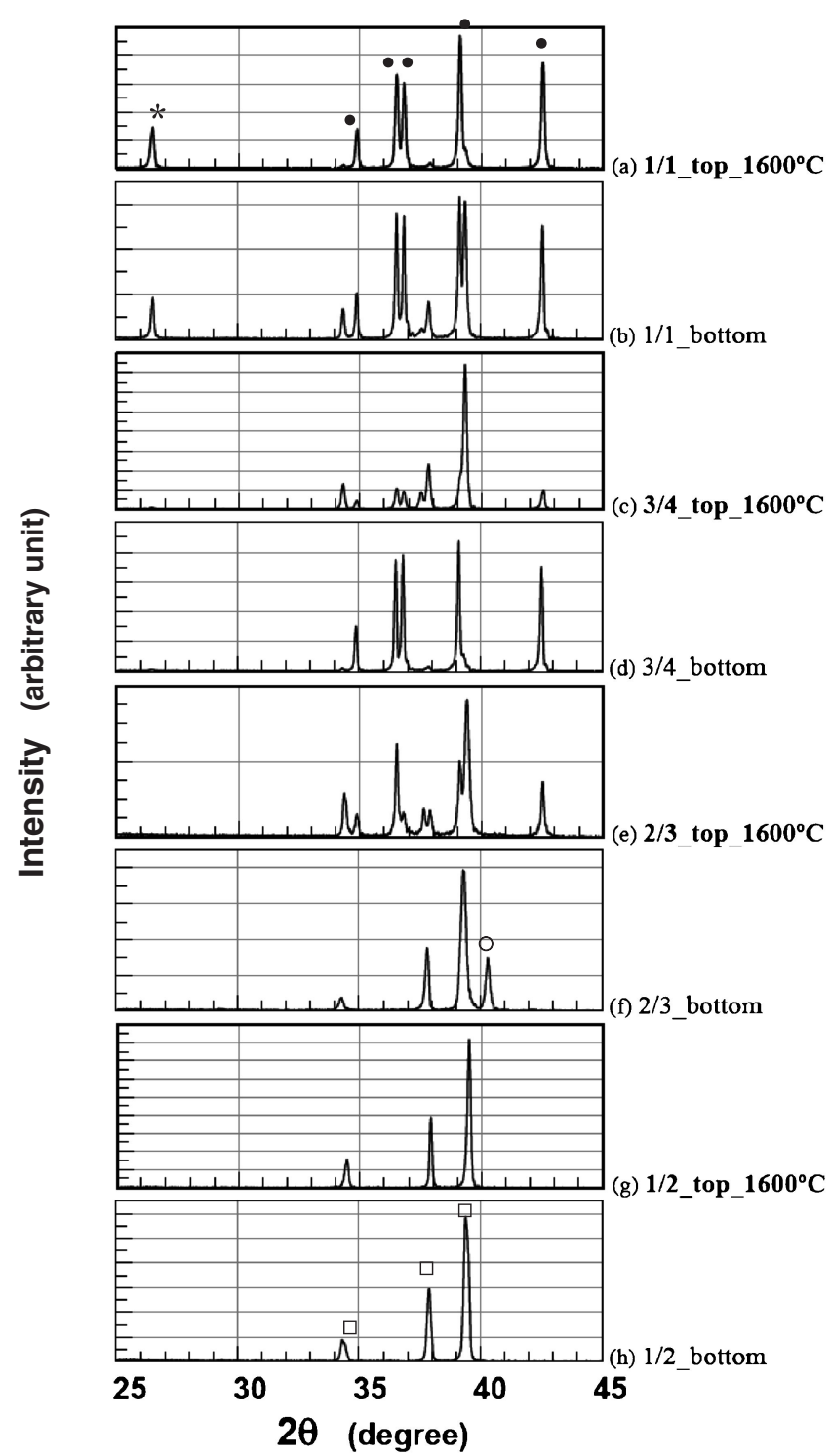

Fig. 1 The XRD patterns $(\mathrm{Cu} K \alpha)$ of the top and the bottom surfaces of the pellets of graphite/molybdenum powder mixtures with $\mathrm{C} / \mathrm{Mo}$ atom ratios, $1 / 1,3 / 4,2 / 3$ and $1 / 2$, heated to $1600^{\circ} \mathrm{C}$ in the solar furnace with the initial ultra-fast heating rate. (๑) $\eta-\mathrm{MoC}_{1-x},(\square) \beta-\mathrm{Mo}_{2} \mathrm{C},(\bigcirc) \mathrm{Mo},\left(^{*}\right)$ graphite.

Typical SEM appearances of the top surface of the test pieces processed at $1600^{\circ} \mathrm{C}$ are summarised in Fig. 3 and those processed at " $2500^{\circ} \mathrm{C}$ " in Fig. 4.

It is noticed in Fig. 3 that the top surface of the test pieces processed at $1600^{\circ} \mathrm{C}$ yielded hexagonal $\eta-\mathrm{MoC}_{1-x}$ phase as the principal phases judging from appearance showing epitaxial growth of hexagonal columns (see Figs. 3(c), (f) and (i)). It is also noticed in Fig. 3 that fraction of the porosity in the test piece tended to diminish with the decreasing $\mathrm{C} / \mathrm{Mo}$ atom ratio on going from $1 / 1$ to $1 / 2$. Figure 3 also shows that clear gaps were visible among the neighbouring grains. No such hexagonal surface morphology was detected for the SEM appearances of the $\mathrm{C} / \mathrm{Mo}=1 / 2$ test piece top surface processed at $1600^{\circ} \mathrm{C}$ (Fig. 3(j)-(1)) that yielded single-phase $\beta-\mathrm{Mo}_{2} \mathrm{C}$ phase (Fig. 1(g)).

In fact, it is a bit peculiar that $\eta-\mathrm{MoC}_{1-x}$ phase emerged as the principal phase at the top surface of the test pieces

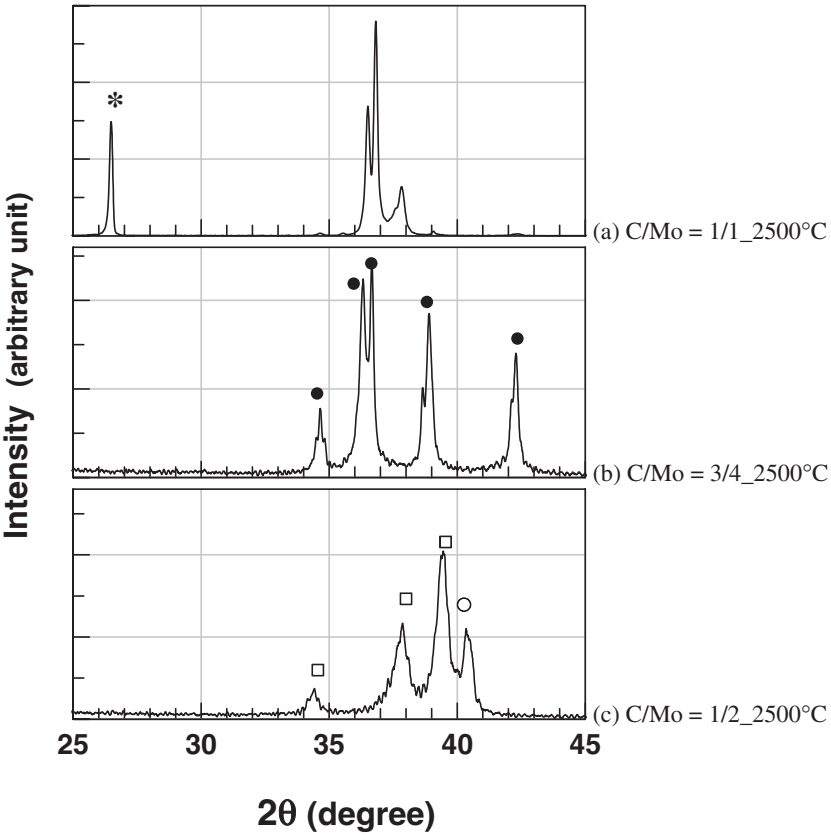

Fig. 2 The XRD patterns $(\mathrm{Cu} K \alpha)$ of the top surfaces of the pellets of graphite/molybdenum powder mixtures with $\mathrm{C} / \mathrm{Mo}$ atom ratios, 1/1, 3/4 and $1 / 2$, heated to $2500^{\circ} \mathrm{C}$ or higher at a focal spot in the solar furnace with the initial ultra-fast heating rate. $(\bigcirc) \eta-\mathrm{MoC}_{1-x},(\square) \beta-\mathrm{Mo}_{2} \mathrm{C},(\bigcirc) \mathrm{Mo},\left(^{*}\right)$ graphite.

Table 1 List of Mo carbide phases detected by XRD in the test pieces prepared under different conditions of processing temperature and of $\mathrm{C} / \mathrm{Mo}$ atom ratio in the starting material. The results for the test pieces treated at $1900^{\circ} \mathrm{C}$ were taken from our preceding work. ${ }^{1)}$

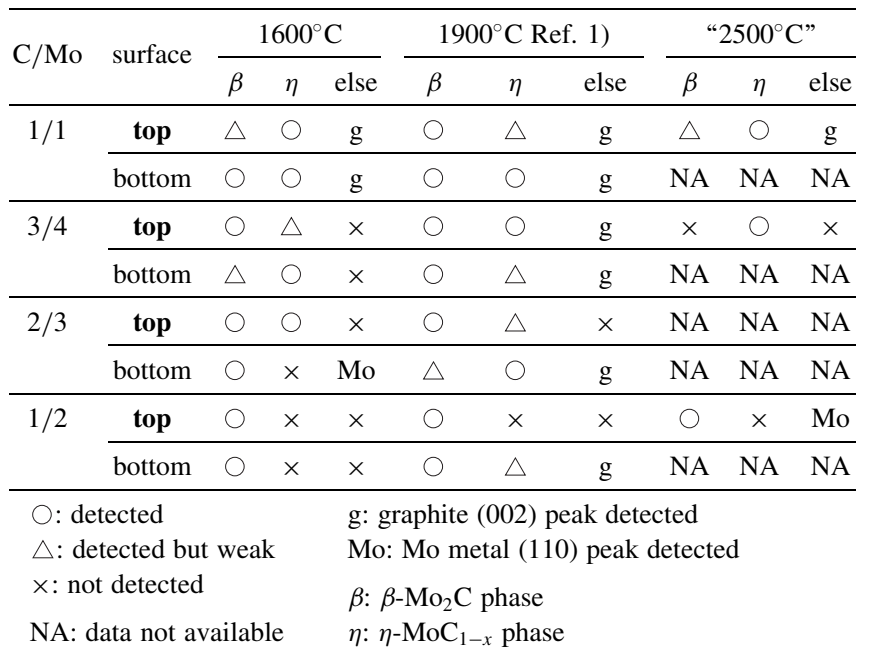

with $\mathrm{C} / \mathrm{Mo}$ equal to or higher than $2 / 3$ processed at $1600^{\circ} \mathrm{C}$ noting that stability range of $\eta-\mathrm{MoC}_{1-x}$ phase is defined to be no less than $1655^{\circ} \mathrm{C}$ in the available equilibrium phase diagrams. ${ }^{3-5)}$ The similar result was obtained by our earlier attempt of synthesising Mo carbide starting from $\mathrm{C} / \mathrm{Mo}$ powder mixtures with excess carbon $(\mathrm{C} / \mathrm{Mo}=1.5)$ at $1600^{\circ} \mathrm{C}$ using a solar furnace at PSA (Plataforma Solar de Almería, Tabernas (Spain)) ${ }^{11)}$ as well as in our more recent work using the solar furnace at PROMES-CNRS. ${ }^{2)}$ At the time of work at PSA about a decade ago, we tentatively interpreted the observed peculiarity in terms of some kind of photochemical effect. ${ }^{11)}$ However, we are still unable 


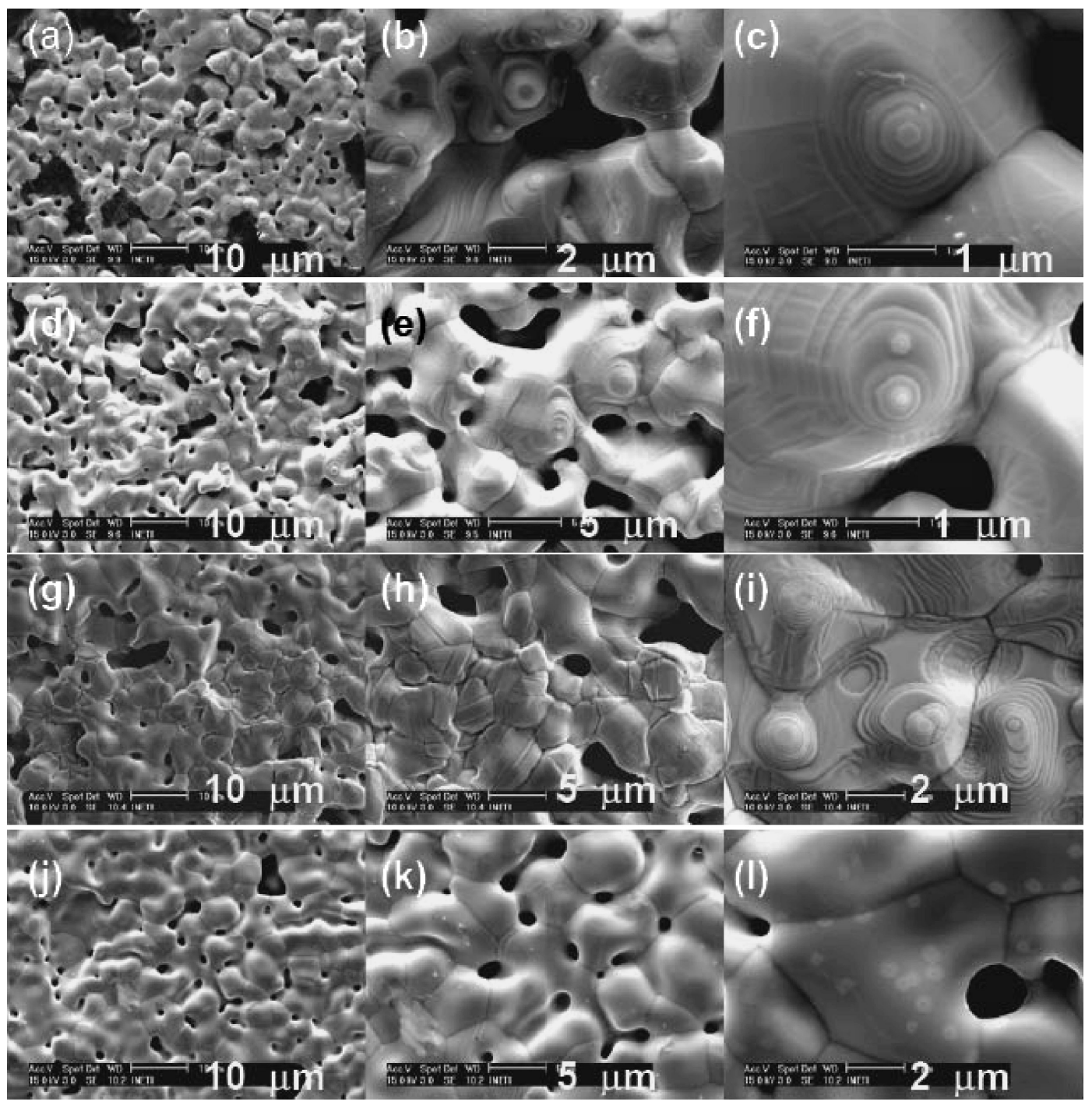

Fig. 3 Typical SEM appearances of the top surfaces of the $\mathrm{C} / \mathrm{Mo}=1 / 1,3 / 4,2 / 3$ and $1 / 2$ specimens heated to $1600^{\circ} \mathrm{C}$. (a)-(c): $\mathrm{C} / \mathrm{Mo}=1 / 1,(\mathrm{~d})-(\mathrm{f}): \mathrm{C} / \mathrm{Mo}=3 / 4,(\mathrm{~g})-(\mathrm{i}): \mathrm{C} / \mathrm{Mo}=2 / 3,(\mathrm{j})-(\mathrm{l}): \mathrm{C} / \mathrm{Mo}=1 / 2$.

to verify the involvement of photochemical effect or not to appreciate the observed peculiarity and accordingly we still have no clear-cut explanation on this aspect. We feel it desirable to undertake solar heating experiment using coloured filter to cut away some frequency range of solar beam to look into this aspect. We proposed another tentative interpretation suggesting that the excessively fast heating rate realised at the onset of the heating in the solar furnace at PROMES-CNRS might be the possible cause for this. ${ }^{2)}$ Anyway, neither of these tentative interpretations ${ }^{2,11)}$ is considered to be convincing conclusive explanation for why $\eta$ - $\mathrm{MoC}_{1-x}$ phase yielded in solar carbide synthesis for Mo at $1600^{\circ} \mathrm{C}$. Thus, this aspect must be elucidated by future work.

In our earlier publication, ${ }^{11)}$ hexagonal $\eta-\mathrm{MoC}_{1-x}$ phase was cited as $\alpha-\mathrm{MoC}_{1-x}$ and cubic $\alpha-\mathrm{MoC}_{1-x}$ as $\beta-\mathrm{MoC}_{1-x}$, respectively, accepting the older nomenclature for these carbide phases used by Storms ${ }^{3)}$ rather than newer one., ${ }^{4,5}$ Thus, special attention must be taken in this respect on reading our earlier publication ${ }^{11)}$ for the purpose of comparing with the discussions presented herein as well as in our preceding publication. ${ }^{1)}$
From the SEM pictures in Fig. 3, unit powder diameter of the Mo was largely in the single-digit micron-meter $(\mu \mathrm{m})$ order in accordance with the nominal powder size specification of around $2 \mu \mathrm{m}$. The graphite particles size also appeared to be in the single-digit $\mu \mathrm{m}$ range, while the nominal size specification was simply $<50 \mu \mathrm{m}$, judging from the size of the pores that were considered to emerge as the diffusion of graphite to the neighbouring metallic Mo to yield Mo carbide phases.

To verify the above aspect concerning the SEM particle size inspection results, particle size distributions of the raw materials were measured using CILAS 1064 liquid granulometer. The mean particle size $d_{50}$ was determined to be $8.0 \pm 0.6 \mu \mathrm{m}$ for Mo powders and $6.9 \pm 0.4 \mu \mathrm{m}$ for graphite powders.

Although no XRD evidence of formation of cubic $\alpha$ $\mathrm{MoC}_{1-x}$ phase was detected under any examined experimental condition, careful SEM inspection of the melted top surface of the $\mathrm{C} / \mathrm{Mo}=3 / 4$ test piece processed to a temperature exceeding $2500^{\circ} \mathrm{C}$ showed localized development of square surface pattern as exhibited in Fig. 5(b) that might be considered as the evidence of formation of 

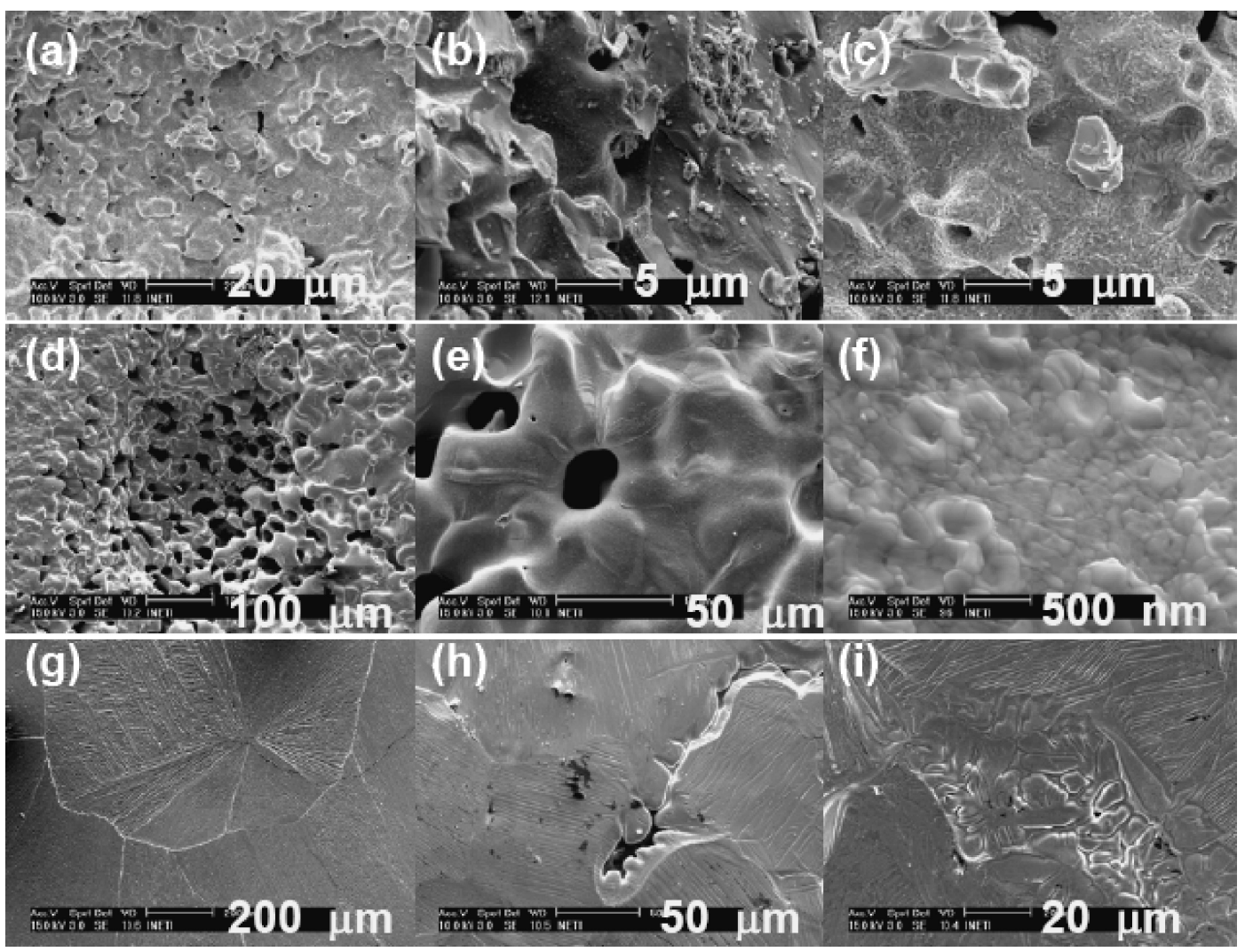

Fig. 4 Typical SEM appearances of the top surfaces of the $\mathrm{C} / \mathrm{Mo}=1 / 1,3 / 4$ and $1 / 2$ specimens heated to $2500^{\circ} \mathrm{C}$ or higher. (a)-(c): $\mathrm{C} / \mathrm{Mo}=1 / 1,(\mathrm{~d})-(\mathrm{f}): \mathrm{C} / \mathrm{Mo}=3 / 4,(\mathrm{~g})-(\mathrm{i}): \mathrm{C} / \mathrm{Mo}=1 / 2$.

cubic $\alpha-\mathrm{MoC}_{1-x}$ phase at least temporarily. Judging from the typical surface appearances of this same test piece exhibited as Figs. 4(d)-(f) and the failure to detect any XRD peak identifiable as $\alpha-\mathrm{MoC}_{1-x}$, the volume fraction of the formed $\alpha-\mathrm{MoC}_{1-x}$ must have been insignificant compared with that of $\eta-\mathrm{MoC}_{1-x}$ or have been lost by dissociation to $\eta-\mathrm{MoC}_{1-x}$ during cooling on account of insufficiently slow rate of quenching down to ambient temperature. Failed detection of XRD peak identifiable as $\alpha-\mathrm{MoC}_{1-x}$ in this test piece might be also the consequence of slight extent of surface polishing of the test piece to ensure flatness of the surface before the XRD characterisation to lead to loss of the surface layer containing the $\alpha-\mathrm{MoC}_{1-x}$.

Metallic Mo was detected at the bottom surface of the $\mathrm{C} / \mathrm{Mo}=2 / 3$ test piece processed at $1600^{\circ} \mathrm{C}$ (Fig. 1(f)) as well as at the top surface of the $\mathrm{C} / \mathrm{Mo}=1 / 2$ test piece heated to a temperature higher than $2500^{\circ} \mathrm{C}$ (Fig. 2(c)). The former must represent the un-reacted Mo on account of relatively low temperature of the reaction at the test piece bottom side compared with that at the top side of the same test piece but the latter might represent the expelled metallic Mo during cooling out of the once formed $\beta-\mathrm{Mo}_{2} \mathrm{C}$.

In Fig. 2(b), satellite peak is detectable at $2 \theta=38.8^{\circ}$ but, as far as the binary Mo-C system is concerned (cf. Table 1 in Ref. 1)), there is no compound to yield XRD peak at this position. Satellite peak is also detectable in Fig. 2(b) at $2 \theta=42.1^{\circ}$ which might represent the remnant of cubic $\alpha-\mathrm{MoC}_{1-x}$ phase judging from nontypical localised SEM appearances in Fig. 5 showing cubic morphology.
Insistent presence of sub-carbide phase, $\beta-\mathrm{Mo}_{2} \mathrm{C}$, even in the test pieces started at the $\mathrm{C} / \mathrm{Mo}$ atom ratios higher than $1 / 2$ at any examined processing temperature was quite intriguing. The similar situation was experienced for the W-C system. ${ }^{6-8)}$ Probable cause for the preferential formation of the sub-carbide phase and its insistent presence during heating to a higher temperature at gross $\mathrm{C} / \mathrm{M}$ ratio in the test piece higher than $1 / 2$ might be interpreted with reference to the electron band theory calculation results reported by Hugosson et al. ${ }^{12,13)}$ claiming that, for $\mathrm{M}_{\mathrm{m}} \mathrm{C}_{\mathrm{n}}$ type carbide phases for $\mathrm{M}=\mathrm{Mo}$ and $\mathrm{W}$, the electronic energy difference among different carbide phases is quite small and thence, once some carbide phase was formed during the processing condition, it would remain insistently without being converted to another phase with truly stable state in thermodynamic terms even when the conditions were shifted to the range under which the other carbide phase would be stable thermodynamically.

Under the condition of ultra-fast heating rate realised at the onset of the heating in the solar furnace at PROMESCNRS in Odeillo, sub-carbide $\mathrm{Mo}_{2} \mathrm{C}$ would form preferentially during initial stage of heating by diffusion of graphite into Mo metal lattice (judging from SEM pictures summarised in Figs. 3 and 4). In the test pieces with $\mathrm{C} / \mathrm{Mo}$ ratio greater than $1 / 2$, direct physical contact between the formed $\mathrm{Mo}_{2} \mathrm{C}$ and the residual graphite might be lost and, if such was the case, even if graphite was present in macroscopic sense in the entire test piece, further conversion of the once formed $\mathrm{Mo}_{2} \mathrm{C}$ to $\eta$ - or $\alpha-\mathrm{MoC}_{1-x}$ phase would not proceed because of the lost direct contact 

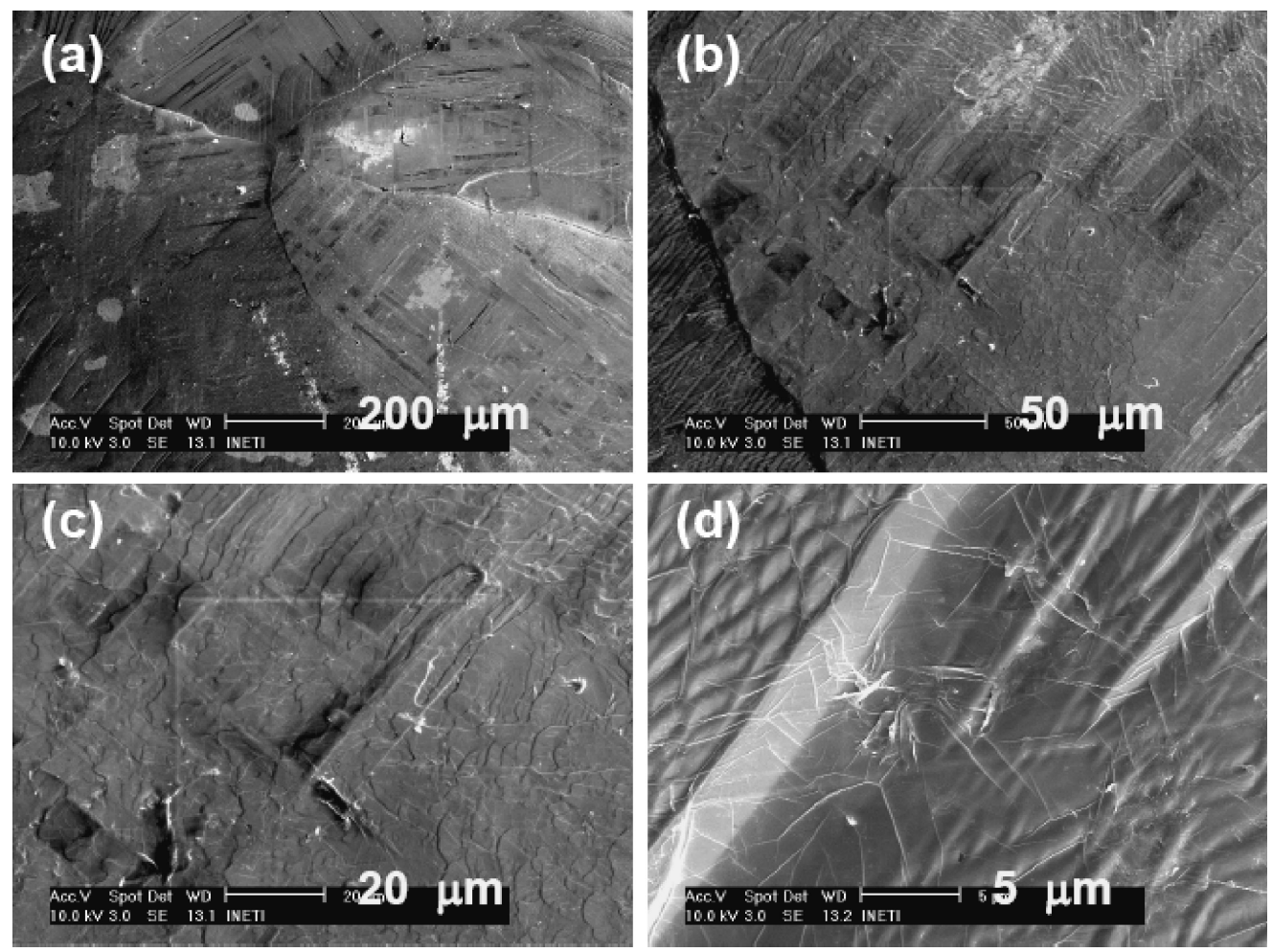

Fig. 5 Non-typical localized SEM appearances detected over the top surface of the $\mathrm{C} / \mathrm{Mo}=3 / 4$ specimen heated to $2500^{\circ} \mathrm{C}$ or higher showing square surface pattern, rather than hexagonal, indicative of possible formation of cubic $\alpha-\mathrm{MoC}_{1-x}$ phase.

between the formed $\beta-\mathrm{Mo}_{2} \mathrm{C}$ particles and the residual graphite.

Such preferential formation of sub-carbide phase during the solar carbide synthesis was experienced for $\mathrm{M}=\mathrm{V}$ ( $\mathrm{Va}$ group metal) under condition of presence of excess free carbon in the reaction product. ${ }^{14)}$ For the binary V-C system, the mono-carbide phase $\mathrm{VC}$ is incomparably more stable thermodynamically than the sub-carbide phase $\mathrm{V}_{2} \mathrm{C}$ and correspondingly the once formed $\mathrm{V}_{2} \mathrm{C}$ was fully converted to $\mathrm{VC}$ by prolonged heating ${ }^{14)}$ in contrast to the situations with $\mathrm{M}=\mathrm{Mo}$ and $\mathrm{W}$ in which $\mathrm{M}_{2} \mathrm{C}$ insisted to remain in the reaction product even after prolonged heating to 90 min. $^{6-8)}$

\section{Conclusions}

From the experimental evidences acquired in the present work together with those obtained in the earlier works, ${ }^{1,2}$ ) following conclusions were drawn concerning the formation conditions for carbide phases of Mo under solar radiation heating with ultra-fast initial heating from ambient temperature to the processing temperature between $1600^{\circ} \mathrm{C}$ and $2500^{\circ} \mathrm{C}$ :

(1) Under any examined condition, formation of $\beta-\mathrm{Mo}_{2} \mathrm{C}$ phase was preferential.

(2) Single-phase hexagonal $\eta$-MoC $1-x$ was prepared only from $\mathrm{C} / \mathrm{Mo}=3 / 4$ test piece processed at $2500^{\circ} \mathrm{C}$ or higher.

(3) Single-phase $\beta$ - $\mathrm{Mo}_{2} \mathrm{C}$ was synthesised from $\mathrm{C} / \mathrm{Mo}=$ $1 / 2$ test piece at the processing temperature $1600^{\circ} \mathrm{C}$.

(4) No XRD evidence of formation of cubic $\alpha-\mathrm{MoC}_{1-x}$ phase was detected under any examined condition
(Table 1; Figs. $1 \& 2$ ) whereas SEM surface inspection for the melted top surface of the $\mathrm{C} / \mathrm{Mo}=3 / 4$ test piece showed evidence of formation of some cubic phase (Fig. 5(b)) implying the necessity of very high rate of quenching to ambient temperature from the reaction temperature in order to retain the once formed cubic $\alpha-\mathrm{MoC}_{1-x}$ phase at ambient temperature.

(5) Very careful control over the $\mathrm{C} / \mathrm{Mo}$ ratio in the starting material as well as processing temperature must be taken to synthesise single-phase Mo carbide with desired constitution.

\section{Acknowledgement}

The authors would like to thank Mrs. Teresa Marcelo in INETI for her dedicated assistance in acquiring SEM surface pictures of the specimen materials.

\section{REFERENCES}

1) B. Granier, J.-M. Badie, F. Almeida Costa Oliveira, T. Magalhães, N. Shohoji, L. Guerra Rosa and J. Cruz Fernandes: Mater. Trans. 49 (2008) 2673-2678.

2) N. Shohoji, J.-M. Badie, B. Granier, F. Almeida Costa Oliveira, J. Cruz Fernandes and L. Guerra Rosa: Int. J. Refractory Met. Hard Mater. 25 (2007) 220-225.

3) E. K. Storms: The Refractory Carbides, New York (Academic Press, 1967).

4) E. Rudy, St. Windisch, A. J. Stosick and J. R. Hoffman: Trans. Metall. Soc. AIME 239 (1967) 1247-1267.

5) T. Ya. Velikanova, V. Z. Kublii and B. V. Khaenko: Soviet Powder Metallurgy and Metal Ceramics (translated from Poroshkovaya Metallurgiya, Kiev) 27 (1988) 891-896.

6) F. Almeida Costa Oliveira, J. Cruz Fernandes, J.-M. Badie, B. Granier, 
L. Guerra Rosa and N. Shohoji: Int. J. Refractory Met. Hard Mater. 25 (2007) 101-106.

7) F. Almeida Costa Oliveira, B. Granier, J.-M. Badie, J. Cruz Fernandes, L. Guerra Rosa and N. Shohoji: Int. J. Refractory Met. Hard Mater. 25 (2007) 351-357.

8) S. Dias, F. Almeida Costa Oliveira, B. Granier, J.-M. Badie, J. Cruz Fernandes, L. Guerra Rosa and N. Shohoji: Mater. Trans. 48 (2007) 919-923.

9) J. Rodríguez, D. Martínez, L. Guerra Rosa, J. Cruz Fernandes, P. M. Amaral and N. Shohoji: J. Solar Energy Eng. 123 (2001) 109-116.

10) J. Cruz Fernandes, C. Anjinho, P. M. Amaral, L. Guerra Rosa, J Rodríguez, D. Martínez, F. Almeida Costa Oliveira and N. Shohoji:
Mater. Chem. Phys. 77 (2002) 711-718.

11) L. Guerra Rosa, J. Cruz Fernandes, P. M. Amaral, D. Martínez, J. Rodríguez and N. Shohoji: Int. J. Refractory Met. Hard Mater. 17 (1999) 351-356.

12) H. W. Hugosson, O. Eriksson and B. Johansson: Proc. Int. Conf. on Solid-Solid Phase Transformations '99 (JIMIC-3), ed. by M. Koiwa, K. Otsuka, T. Miyazaki, (Jpn Inst. Met., 1999) pp. 637-640.

13) H. W. Hugosson, B. Johansson, L. Nortström, U. Jansson and O. Eriksson: Frontiers in Interdisciplinary Physics, (IARS Press, La Jolla, CA, 1999) pp. 1-17.

14) J. Cruz Fernandes, F. Almeida Costa Oliveira, B. Granier, J.-M. Badie, L. Guerra Rosa and N. Shohoji: Solar Energy 80 (2006) 1553-1560. 